OPEN ACCESS

Edited by:

Zhi Wang,

Innovation Academy for Precision Measurement Science and

Technology (CAS), China

Reviewed by:

Naga Raju Maddela,

Technical University of Manabi,

Ecuador

Xiaohui Liu,

Chinese Research Academy of Environmental Sciences, China

*Correspondence:

Dorcas Oladayo Fatoba dorcas4c@gmail.com

Specialty section:

This article was submitted to

Toxicology, Pollution and the

Environment,

a section of the journal

Frontiers in Environmental Science

Received: 01 August 2021 Accepted: 29 November 2021

Published: 04 January 2022

Citation:

Fatoba DO, Amoako DG, Abia ALK and Essack SY (2022) Transmission of Antibiotic-Resistant Escherichia coli from Chicken Litter to Agricultural Soil.

Front. Environ. Sci. 9:751732.

doi: 10.3389/fenvs.2021.751732

\section{Transmission of Antibiotic-Resistant Escherichia coli from Chicken Litter to Agricultural Soil}

\author{
Dorcas Oladayo Fatoba ${ }^{1 *}$, Daniel Gyamfi Amoako ${ }^{1,2}$, Akebe Luther King Abia ${ }^{1}$ and \\ Sabiha Yusuf Essack ${ }^{1}$
}

${ }^{1}$ Antimicrobial Research Unit, College of Health Science, University of KwaZulu-Natal, Durban, South Africa, ${ }^{2}$ Sequencing Core Facility, National Health Laboratory Service, National Institute for Communicable Diseases, Johannesburg, South Africa

A growing concern regarding the use of animal manure as fertilizer is the contamination of soil, plants, and the environment with a variety of antibiotic-resistant and pathogenic bacteria. This study quantified and characterized the antibiotic resistance profiles of Escherichia coli in soil before and after chicken litter application to determine the impact of manure on the soil resistome. Litter and soil samples were collected from a sugarcane field before and after litter application. E. coli was isolated and quantified using the Colilert ${ }^{\circledR}-18$ /Quanti-tray ${ }^{\circledR} 2000$ and 10 randomly selected isolates from the positive wells of each Quanti-tray were putatively identified on eosin methylene blue agar. Real-time PCR was used to confirm the isolates by targeting the uidA gene. Antibiotic susceptibility test against 18 antibiotics was conducted using the disk diffusion method, and the multiple antibiotic resistance index was calculated. Soil amendment with chicken litter significantly increased the number of antibiotic-resistant $E$. coli in the soil. Among the $126 \mathrm{E}$. coli isolates purified from all the samples, $76 \%$ showed resistance to at least one antibiotic, of which $54.2 \%$ were multidrug-resistant (MDR). The highest percentage resistance was to tetracycline $(78.1 \%)$, with the least percentage resistance $(3.1 \%)$ to imipenem, tigecycline, and gentamicin. The isolates also showed resistance to chloramphenicol (63.5\%), ampicillin (58.3\%), trimethoprim-sulfamethoxazole (39.6\%), cefotaxime (30.2\%), ceftriaxone (26.0\%), cephalexin (20.8\%), cefepime (11.5\%), amoxicillin-clavulanic acid (11.5\%), cefoxitin (10.4\%), Nalidixic acid (9.4\%), amikacin (6.3\%), and ciprofloxacin (4.2\%). Of the 54.2\% (52/96) MDR, the highest number was isolated from the litter-amended soil $(61.5 \%)$ and the least isolates from soil samples collected before litter application (1.9\%). The relatively higher mean MAR index of the litter-amended soil (0.14), compared to the soil before the amendment (0.04), suggests soil pollution with antibiotic-resistant $E$. coli from sources of high antibiotic use. E. coli could only be detected in the soil up to 42 days following manure application, making it a suitable short-term indicator of antibiotic resistance contamination. Notwithstanding its relatively short detectability/survival, the application of chicken litter appeared to transfer antibiotic-resistant E. coli to the soil, enhancing the soil resistome and highlighting the consequences of such agricultural practices on public health.

Keywords: $E$ coli, multidrug-resistance, chicken litter, litter-amended soil, unamended soil, environment, transmission, pollution 


\section{INTRODUCTION}

The increasing prevalence of antibiotic-resistant bacteria (ARB) in the environment is a growing global threat to public health in the 21st century (Udikovic-Kolic et al., 2014; Wellcome Trust, 2018). The misuse and overuse of antibiotics in food-animal production contributes to the emergence and subsequent spread of antibiotic resistance from animals to the environment (Laxminarayan et al., 2013; WHO 2020). A significant route by which ARB enter the environment and the food chain is through manure from antibiotic-treated animals applied to agricultural soil (Heuer et al., 2011; Marti et al., 2013). However, the impact of this agricultural practice on the soil resistome is not well known, particularly in African countries.

Chicken litter is often applied to agricultural soil as a substitute for inorganic fertilisers to meet the growing demand for crops and improve soil fertility, particularly in organic farming (Jechalke et al., 2013; Marti et al., 2013; Atidégla et al., 2016). Also, the application of chicken litter to agricultural soil as organic fertiliser is the cheapest means of disposing the large volumes of poultry waste generated from the rapidly growing poultry industry worldwide (Kyakuwaire et al., 2019). Furthermore, chicken litter, a mixture of chicken faeces, waste feed, wood shavings, and other small invertebrates, is a major soil amendment that improves and maintains the chemical, physical, and biological soil properties (Brye et al., 2004).

A growing concern about the application of untreated animal manure to agricultural soil is the possibility of contamination with pathogenic ARB and antibiotic resistance genes (ARGs), as animal manure is considered a significant reservoir of both enteric and pathogenic ARB and ARGs (Robins-Browne, 2005; Johnson et al., 2016). Previous studies that investigated the impact of animal manure on soil resistome demonstrated that fertilisation with animal manure resulted in the appearance or increased level and diversity of ARB and ARGs in soils (Jensen et al., 2013; Chen et al., 2016b; Fatoba et al., 2021; Sun et al., 2021). Jensen et al. (2013) reported the appearance of E. coli in soil after the application of animal slurry to three Danish agricultural fields. Additionally, Chen and others (2016b) observed a significant increase in the bacterial diversity and the abundance of tetracyclines genes in the soil following manure amendment in China. Fatoba et al. (2021) also observed an increase in MDR Enterococcus spp. in agricultural soil following chicken litter application. Another study from the United States showed that manure application significantly increased the diversity of surface soil microbiome and resistome and also introduced tetracycline and sulphonamide resistance genes to the soil (Sun et al., 2021).

The addition of ARB and ARGs of animal manure origin to the soil can also lead to horizontal transfer of ARGs between the manure-borne bacteria and the indigenous soil bacteria through mobile genetic elements (MGEs) (Heuer et al., 2011). Gao et al. (2015) tracked E. coli harbouring ESBL genes from pig manure to agricultural soil fertilised with pig manure and showed that MDR ESBL-producing $E$. coli isolates from the manure-amended soil had overlapping phenotypes and over $90 \%$ genetic similarity with strains from the pig manure samples. Seventy and fifty-six percent of the isolates from the manured soil and pig manure, respectively, harboured the IncF-type replicon plasmids, which suggest possible horizontal gene transfer in the soil (Gao et al., 2015).

Moreover, most studies have indicated that such increases are temporal because bacteria from manure are less adapted to soil environments (Sengeløv et al., 2003b; Heuer and Smalla, 2007; Binh et al., 2008; Marti et al., 2014; Muurinen et al., 2017) However, other studies have found certain ARB to survive in manure-amended soil for extended periods (Islam et al., 2004; Merchant et al., 2012; Çekiç et al., 2017). These ARB and ARGs from the manure-amended soil can subsequently enter the food chain through contaminated farm produce or spread to community surface water bodies via run-offs(Marti et al., 2013; Zhang et al., 2019), posing severe human health risks. Several infection outbreaks have been linked to $E$. coli in food contaminated by animal manure (Atidégla et al., 2016; Yang et al., 2017; Shonhiwa et al., 2019).

There is a paucity of information on the environmental dimensions of AMR in Africa, as most of the AMR surveillance and research focuses on the prevalence of ARB in humans and food animals (farm-to-fork) (Mbelle et al., 2019; McIver et al., 2020; Abdalla et al., 2021). However, a substantial number of ARB can be transferred to the soil via animal manure application, and attempts to identify them may not be financially and technologically feasible. Therefore, identifying an organism suitable to be an indicator of such pollution is necessary. E. coli has been used as an indicator of faecal pollution for centuries. Recently, the World Health Organization (WHO) has recommended using $E$. coli to trace AMR because its molecular mechanisms of resistance are well characterised (WHO, 2020). However, several studies have reported on the relatively shorter duration of survival of $E$. coli in the environment compared with other organisms (Sengeløv et al., 2003a; Bolton et al., 2011; Abia et al., 2015b). In addition, a previous study showed that Enterococcus could be found in litter amended soils up to 105 days following manure application (Fatoba et al., 2021). Therefore, this study investigated the potential transmission of antibiotic-resistant $E$. coli from chicken litter to agricultural soil and sought to determine how long E. coli could be detected in litter amended soil following chicken litter application. We evaluated the prevalence, antibiotic resistance profiles, and the MAR indices of E. coli isolated from chicken litter and the soil of a sugarcane field before and after chicken litter application.

\section{MATERIALS AND METHODS}

\section{Study Site and Sample Collection}

This study was carried out on a sugarcane field located in uMshwathi Local Municipality in uMgungundlovu District, KwaZulu-Natal, South Africa, fertilized with chicken litter. The study site and its surroundings have previously been described (Fatoba et al., 2021). The sample collection was carried out for one hundred and 16 days (October 2018 to February 2019). Soil samples were collected for 5 days before manure application 
(i.e., days 1, 2, 3, 5, and 9). Samples were also collected on the day of manure application over 111 days. Soil samples were collected until no microbial counts were recorded in most of the sampling points at three consecutive sampling rounds. The chicken litter was a mixture of raw chicken faeces and wood shavings from a large-scale chicken farm that supplements feed and water with antibiotics in the uMgungudlovu District. The poultry farmer uses zinc bacitracin, olaquindox, and avilamycin, for growth promotion. Doxycycline, macrolide-lincosamides (tylosin, kitasamycin), enrofloxacin, sulfadiazine-trimethoprim, and zinc bacitracin are used for therapeutic purposes. A detailed sampling regime has previously been described (Fatoba et al., 2021).

\section{Quantification and Purification of E. coli}

E. coli was detected and quantified using the Colilert ${ }^{\circledR}-18 /$ QuantiTray 2000 system (IDEXX Laboratories (Pty) Ltd., Johannesburg, South Africa) according to the manufacturer's guidelines. All the samples collected were processed as previously described by Abia et al. (2015a). Briefly, $5 \mathrm{~g}$ of homogenised soil or litter samples were resuspended in $5 \mathrm{ml}$ sterile distilled water, and the supernatant was analysed using the IDEXX defined substrate multiple tube technique as recommended by the manufacturer. A detailed analysis of the samples' supernatant has been previously described by Fatoba et al. (2021). The most probable number (MPN) of E. coli in $100 \mathrm{ml}$ of sample $(\mathrm{MPN} / 100 \mathrm{ml})$ poured inside the quanti-Tray ${ }^{\circledR}$ 2000 system was calculated from the number of fluorescent (positive) wells per sample as recommended by IDEXX. Corresponding value of $E$. coli counts per grams (MPN/g), was calculated taking into consideration the dilution factor. Following incubation, pure $E$. coli isolates were obtained by subculturing the content of ten randomly selected fluorescent wells repeatedly on Eosin Methylene Blue agar plates (Oxiod, Hampshire, England) and incubating at $37^{\circ} \mathrm{C}$ for $24 \mathrm{~h}$ as previously described (Abia et al., 2015b). The presumptive pure, distinct colonies obtained from the selective media plates were stored in trypticase soy broth (TSB) with $20 \%$ glycerol at $-80^{\circ} \mathrm{C}$ for further analysis.

\section{Molecular Confirmation of the E. coli Isolates}

The stored isolates were revived on nutrient agar. Overnight grown E. coli cultures on nutrient agar plate at $37^{\circ} \mathrm{C}$ were used for the DNA extraction using the boiling method previously described (Dashti et al., 2009). The extracted DNA was stored at $-80^{\circ} \mathrm{C}$ for subsequent analysis. All the $E$. coli isolates were then confirmed by real-time polymerase chain reaction using specific primers sets that targeted the uidA (encoding beta-glucuronidase) gene as described by López-Saucedo et al. (2003) using the forward and reverse primers $5^{\prime}$-AAAACGGCAAGAAAAAGC AG-3' and 5'-ACGCGTGGTTAACAGTCTTGCG-3', respectively. The positive control used was E. coli ATCC 25922 (American Type Culture Collection, Manassas, VA, United States), and the no-template control was the reaction mixture without template DNA. The PCR protocols were as previously described (Abia et al., 2015b).

\section{Antibiotic Susceptibility Testing}

The antibiotic susceptibility test of the $E$. coli isolates was carried out according to the Clinical and Laboratory Standards Institute guidelines (CLSI, 2020) using the disk diffusion method on a panel of 18 antibiotics (Figures 1,2). Zones of inhibition were interpreted according to CLSI breakpoints except for tigecycline $(15 \mu \mathrm{g})$ and cephalexin $(30 \mu \mathrm{g})$, where the European Committee on Antimicrobial Susceptibility Testing (EUCAST) breakpoints were used. Multidrug resistance is defined as resistance to at least one drug in three or more different classes of antibiotics. E. coli ATCC 25922 was used as the control strain. The multiple antibiotic resistance (MAR) index of each isolate was calculated as $a / b$, where $a$ is the number of antibiotics to which a tested isolate expressed resistance, and $b$ is the number of antibiotics to which the isolate has been evaluated for susceptibility (Krumperman, 1983).

\section{Statistical Analysis}

The data on E. coli counts were log-transformed and analysed using Microsoft Excel 2016 and Statistical Package for the Social Science SPSS version 26 (IBM Corporation, Armonk, New York, United States). One-way analysis of variance (ANOVA) and Games-Howell Post-hoc test was used to check for any significant differences in the mean counts of $E$. coli and the number of antibiotic-resistant $E$. coli in the soil before and after litter amendment and the chicken litter. All statistical tests were considered significant at $p<0.05$. For ease of data presentation, the most probable number per Gram (MPN/g) of samples with values $<1$ was considered as 1 for log-transformation and average calculations.

\section{RESULTS}

\section{Mean Concentrations of E. coli}

A total of 193 samples (45 chicken litter and 148 soil) were collected. Among the three sample groups, chicken litter had the highest $(4.09 \mathrm{E}+07 \mathrm{MPN} / \mathrm{g})$ E. coli counts per sample round (Table 1). The overall mean count of $E$. coli in the chicken litter $\left(2.11( \pm 1.29) \times 10^{7} \mathrm{MPN} / \mathrm{g}\right)$ was significantly higher than the litter-amended soil $(p=0.020)$, and the soil samples collected before the litter amendment $(p=0.023)$ (Supplementary Table S1). There was no statistically significant difference $(p=0.999)$ in the overall mean count of $E$. coli in the litter-amended soil (1.51 $\left.( \pm 0.99) \times 10^{7} \mathrm{MPN} / \mathrm{g}\right)$ and the soil samples collected before the litter amendment $\left(1.52( \pm 0.72) \times 10^{7} \mathrm{MPN} / \mathrm{g}\right)$ (Supplementary Table S1). The E. coli counts in the soil and the stored chicken litter fluctuated throughout the sampling period. No E. coli was detectable in the soil 49 days after the litter amendment.

\section{Prevalence and Antibiotic Susceptibility Profiles of the $E$. coli Isolates}

A total of $126 \mathrm{E}$. coli isolates were recovered from all the positive samples, with 88 from the litter-amended soil, 10 from soil samples before the litter amendment, and 28 from the chicken litter. Seventysix percent (96/126) of the $E$. coli isolates displayed resistance to at 
TABLE 1 | Mean E. coli counts ((MPN/g) throughout the sample collection.

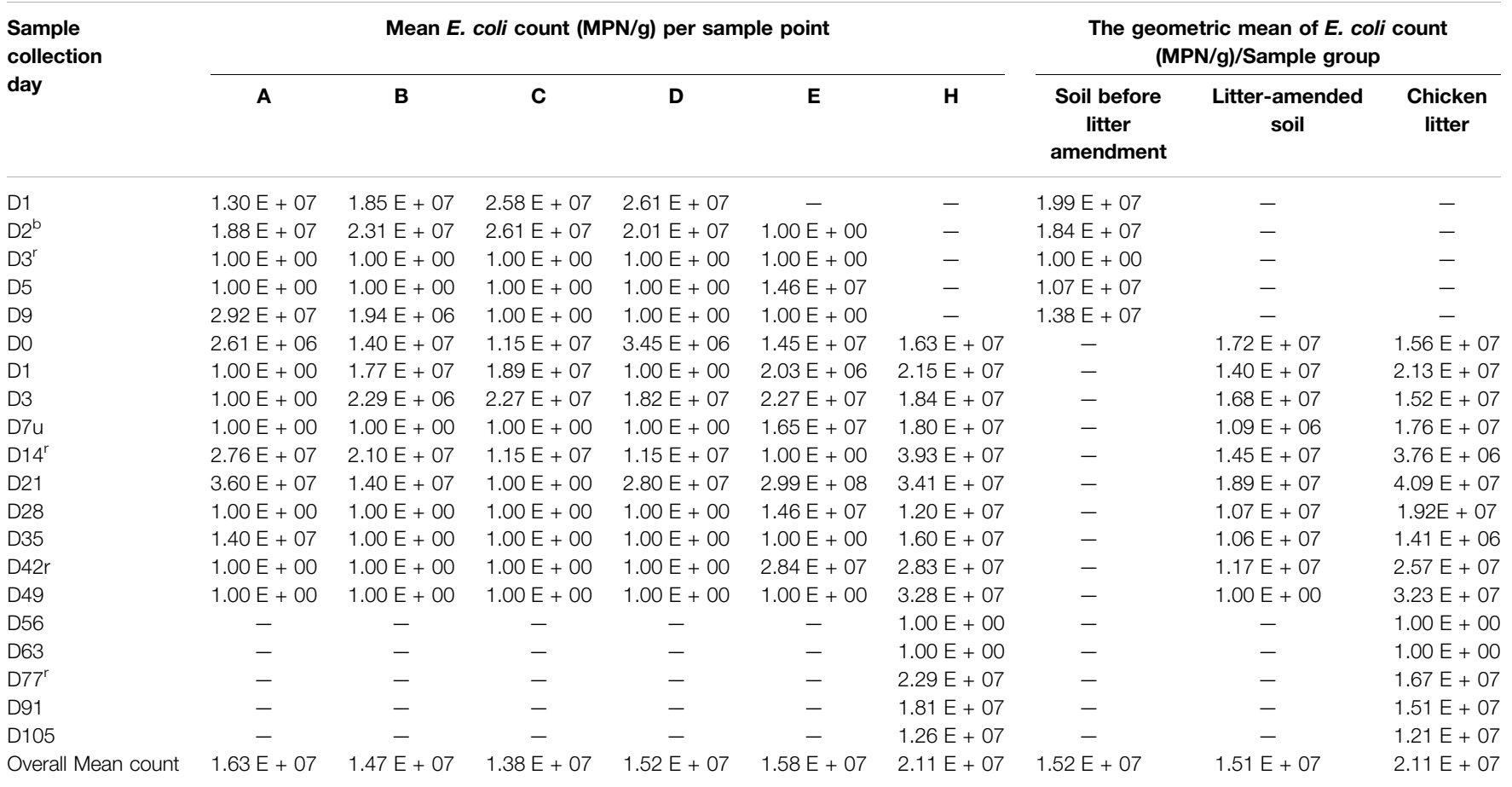

- Sample not collected. The farm was burnt (b) on day 2 (D2), chicken litter, and urea (U) salt was applied on day 0 (DO) and day 7 (D7) respectively. E. coli reduced to detection limit in soil on day 49 (D49).

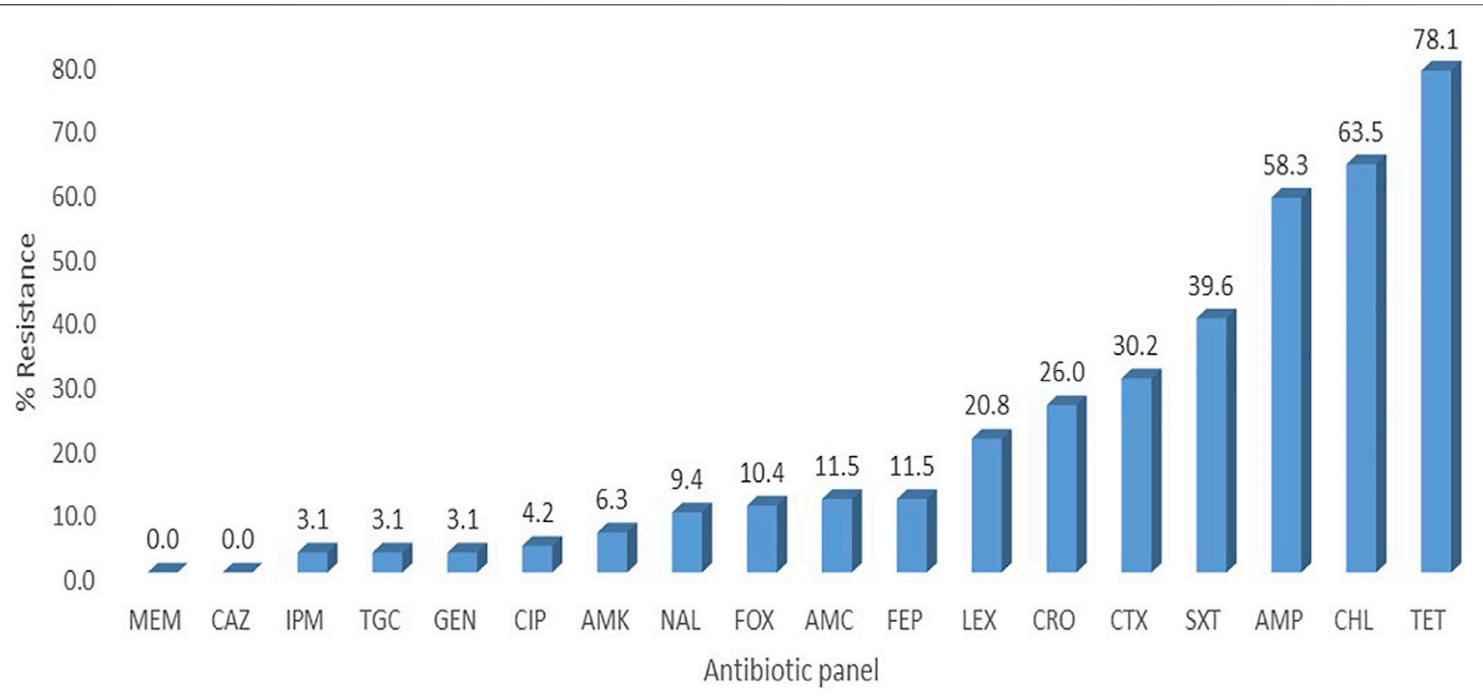

FIGURE 1 | Percentage resistance of the $\boldsymbol{E}$. coli isolates. LEX-Cefalexin, FEP-Cefepime, CTX-Cefotaxime, CAZ-Ceftazidime, AMP-Ampicillin, FOX-Cefoxitin, TGC-Tigecycline, CIP-Ciprofloxacin, TET-Tetracycline, SXT- Trimethoprim-sulfamethoxazole, AMC-Amoxicillin-clavulanic acid, CHL- Chloramphenicol, GENGentamicin, AMK- Amikacin, MEM-Meropenem, CRO-Ceftriaxone, IPM-Imipenem, NAL-Nalidixic acid.

least one of the antibiotics tested. The highest number was recorded in the litter-amended soil $(71.9 \%, 69 / 96)$, followed by the chicken litter $(27.1 \%, 26 / 96)$ and in soil samples collected before the litter amendment $(1 \%, 1 / 96)$. The highest percentage resistance was to tetracycline $(78.1 \%)$, while the least $(3.1 \%)$ was to imipenem, tigecycline, and gentamicin (3.1\%) (Figure 1). In addition, all the isolates were susceptible to meropenem and ceftazidime. Notably, there was an increased detection of $E$. coli isolates resistant to tetracycline, ampicillin, chloramphenicol, and trimethoprimsulfamethoxazole in the soil after the chicken litter application (Figure 2). The overall prevalence of antibiotic-resistant E. coli in the litter-amended soil was statistically significantly higher than in the soil samples before amendment $(p=0.001)$ and chicken litter $(p=0.001)$ (Supplementary Table S2). 


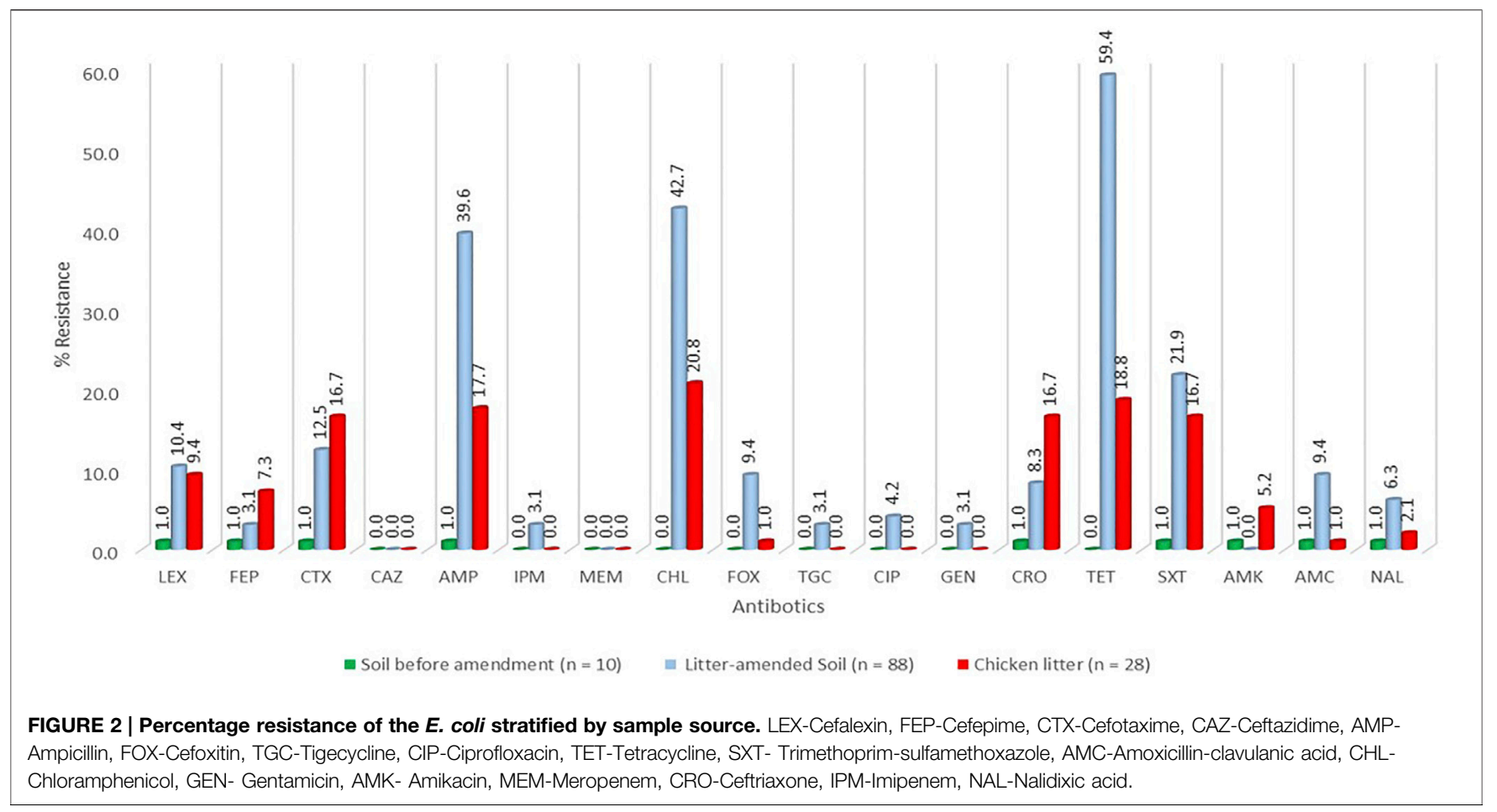

\section{Multidrug Resistance}

Multidrug resistance was evident, and the predominant resistance patterns were ampicillin-chloramphenicol-tetracycline and chloramphenicol-tetracycline-trimethoprim-sulfamethoxazole

(Table 2). In total, 54.2\% (52/96) of the isolates were multidrugresistant, grouped into 21 different resistance patterns. The highest prevalence of MDR was detected in the litter-amended soil $(61.5 \%)$ and the least in isolates from soil samples collected before litter application (1.9\%) (Table 2). Interestingly, two isolates, one from each of the chicken litter and litteramended soil, displayed resistance to ten antibiotics that belong to six and four classes of antibiotics, respectively.

\section{Multiple Antibiotic Resistance (MAR) Index of the $E$. coli Isolates}

The MAR index of all the isolates ranged between 0.11 and 0.56, representing resistance to two and ten antibiotics, respectively (Table 3). Overall, 38.5\% (37/96) of the resistant isolates had a MARI $>0.2$ with the highest rate (51.4\%) in the litter-amended soil and the least in the soil before litter amendment $(2.7 \%)$.

\section{DISCUSSION}

An anthropogenic activity like the application of manure from food animals exposed to antibiotics to soil can increase the burden of AMR in the soil environment, thereby posing a public health threat, particularly when potential pathogenic ARB like E. coli enter the food chain. This study investigated the potential transmission of antibiotic-resistant E. coli from chicken litter to agricultural soil in KwaZulu-Natal, South Africa. The chicken litter amendment increased the bacterial count and the number of antibiotic-resistant isolates in the soil. Antibiotic-resistant $E$. coli was detected in all the sample points and the three sample groups with the highest prevalence in the litter-amended soil. The isolates displayed high percentage resistance to tetracycline, ampicillin, chloramphenicol, and trimethoprim-sulfamethoxazole commonly used in poultry farms. Also, $54.2 \%$ of all the isolates were MDR. The relatively high percentage $(51.4 \%)$ of isolates with MAR index $>0.2$ in the litter-amended soil compared to the soil before the litter amendment $(2.7 \%)$ indicated that the litter amendment resulted in soil contamination with $E$. coli from sources with high use of antibiotics.

\section{Mean Concentrations of $E$. coli}

E. coli is an established indicator of faecal contamination because of its ubiquitous presence in the intestines of animals and its prominence in faecal-contaminated environments (Aarestrup et al., 2008). This explains the highest E. coli count recorded in the chicken litter, making it a potential source of $E$. coli contamination to the receiving environment. There was an increase in E. coli count in the soil at the time (day 0) the chicken litter was applied and days (D3, D14, and D21) after the soil amendment (Table 1). The litter amendment could have contributed to the observed increase, as previous studies have indicated that the addition of animal manure to soil increases the number of viable bacteria in soil by the enrichment of indigenous soil bacteria or addition of manure-borne bacteria (Zhu et al., 2013). 
TABLE 2 | Multidrug-resistance patterns of the $E$. coli isolates.

\begin{tabular}{|c|c|c|c|c|}
\hline Antibiogram & Soil before litter $(n=10)$ & Litter-amended soil $(n=88)$ & Chicken litter $(n=28)$ & Total \\
\hline \multicolumn{5}{|l|}{ Farm burning day (D2) } \\
\hline AMP-AMC-LEX-CTX-CRO-FEP-AMK-SXT & 1 & 0 & 0 & 1 \\
\hline \multicolumn{5}{|l|}{ Day 0 of litter application } \\
\hline AMP-CHL-TET & 0 & 8 & 0 & 8 \\
\hline AMP-CTX-CRO-NAL-CHL-TET & 0 & 1 & 0 & 1 \\
\hline AMP-CTX-CRO-CHL-TET & 0 & 2 & 5 & 7 \\
\hline AMP-CHL-TET-SXT & 0 & 3 & 0 & 3 \\
\hline AMP-CTX-CHL-TET & 0 & 1 & 0 & 1 \\
\hline AMP-CHL-CIP-GEN-TET-SXT & 0 & 1 & 0 & 1 \\
\hline AMP-NAL-CIP-GEN- CHL-TET-SXT & 0 & 1 & 0 & 1 \\
\hline AMP-TET-SXT & 0 & 7 & 0 & 7 \\
\hline \multicolumn{5}{|l|}{ Day 3 after litter application } \\
\hline AMP-AMC-LEX-FOX-CTX-CRO-FEP-TET-SXT & 0 & 1 & 0 & 1 \\
\hline AMP-AMC-LEX-FOX-CTX-CRO-TET-SXT & 0 & 1 & 0 & 1 \\
\hline \multicolumn{5}{|l|}{ Day 7 after litter application } \\
\hline AMP-AMC-LEX-FOX-CTX-CRO-FEP-TET-TGC-SXT & 0 & 1 & 0 & 1 \\
\hline \multicolumn{5}{|l|}{ Day 14 after litter application } \\
\hline AMP-LEX-NAL-CIP-GEN-CHL-TET & 0 & 1 & 0 & 1 \\
\hline AMP-LEX-CTX-CRO-FEP-NAL-CIP-TET-SXT & 0 & 1 & 0 & 1 \\
\hline \multicolumn{5}{|l|}{ Day 21 after litter application } \\
\hline AMP-AMC-TET-SXT & 0 & 1 & 0 & 1 \\
\hline CHL-TET-SXT & 0 & 1 & 7 & 8 \\
\hline AMP-AMC-FOX-TET-SXT & 0 & 1 & 0 & 1 \\
\hline \multicolumn{5}{|l|}{ Day 49 after litter application } \\
\hline AMP-LEX-CTX-CRO-FEP-NAL-AMK-CHL-TET-SXT & 0 & 0 & 1 & 1 \\
\hline AMP-LEX-CTX-CRO-FEP-CHL-TET-SXT & 0 & 0 & 4 & 4 \\
\hline AMP-LEX-CTX-CRO-FEP-NAL-AMK-SXT & 0 & 0 & 1 & 1 \\
\hline \multicolumn{5}{|l|}{ Day 77 after litter application } \\
\hline AMK-CHL-TET-SXT & 0 & 0 & 1 & 1 \\
\hline Total MDR Isolates $(n=52,54.2 \%)$ & 1 (1.9\%) & 32 (61.5\%) & 19 (36.5\%) & 52 \\
\hline
\end{tabular}

LEX-Cefalexin, FEP- cefepime, CTX-Cefotaxime, CAZ-Ceftazidime, AMP-Ampicillin, FOX-Cefoxitin, TGC-Tigecycline, CIP-Ciprofloxacin, TET-Tetracycline, SXT- Trimethoprimsulfamethoxazole, AMC-Amoxicillin-clavulanic acid, CHL- Chloramphenicol, GEN- Gentamicin, AMK- Amikacin, MEM-Meropenem, CRO-Ceftriaxone, IPM-Imipenem, NAL-Nalidixic acid.

TABLE 3 | Multiple antibiotic resistance (MAR) index of the isolates.

\begin{tabular}{lcc}
\hline MAR index & No. of isolates & Percentage (\%) \\
\hline 0.11 & 26 & 27.1 \\
0.17 & 25 & 26.0 \\
0.22 & 10 & 10.4 \\
0.28 & 9 & 9.4 \\
0.33 & 4 & 4.2 \\
0.39 & 2 & 2.1 \\
0.44 & 8 & 8.3 \\
0.50 & 2 & 2.1 \\
0.56 & 2 & 2.1
\end{tabular}

In this study, we observed short-term (42 days) persistence of E. coli in the soil following the amendment suggesting that E. coli can serve as a suitable indicator of short-term faecal pollution in agricultural soil. This finding is consistent with previous reports (Sengeløv et al., 2003a; Binh et al., 2008; Bolton et al., 2011), that indicated that some bacteria from animal manure are less adapted to the soil environment and only survive for a short time (9 days-11 weeks). Several indicator organisms like enterococci, E. coli, faecal coliforms, and Clostridium perfringens are the commonly tested faecal pollution indicators. However, the limitations and strength of each of these indicators suggest that none of these indicator organisms should be used in isolation for predicting the impact of faecal pollution in any environment (Tyagi and Chopra, 2006). E. coli hardly survives under environmental stress such as limited moisture, low organic matter, high and low temperatures (Berry and Miller 2005; Williams et al., 2005). Contrary to E. coli, high densities of enterococci in soils has been attributed, in part, to the more excellent survival abilities of Gram-positive bacteria (e.g., enterococci and staphylococci) than of Gram-negative bacteria (e.g., E. coli, and Pseudomonas spp.) under environmental stresses, particularly desiccation and cellular injury (Bale et al., 1993; Byappanahalli et al., 2012). Fatoba et al., 2021 showed that resistant enterococci were still detectable in the litter-amended soil even at 105 days after chicken litter application. However, E. coli was no longer detectable after day 42 in the current study, suggesting that the long-term impact and accurate monitoring of the soil environment for bacterial contamination from manure-based fertilizers requires a more persistent indicator organism alongside E. coli. Supporting this finding, a previous study of faecal pollution in riverbed sediments in South Africa recommended using Clostridium perfringens alongside E. coli as indicators of faecal pollution in riverbed soil due to its persistence in the environment(Abia et al., 2015b). Although 
E. coli was not recorded in the litter-amended soils after 42 days, some isolates were still recovered from the unapplied chicken litter heap. The survival could be due to the rich nutrient content in the chicken litter, while the disappearance in the litteramended soil could have also been influenced by other farm practices like urea application.

\section{Antibiotic Susceptibility Profiles of the E. coli Isolates}

The use of antibiotics in food animal production has been beneficial for economic and animal health reasons. Thus, different antibiotic classes are used in food-animal production, depending on the purpose (prophylaxis, metaphylaxis, treatment, or growth promotion), the kind of animal, and the country's policies. However, their overuse and misuse have led to increased detection of ARB in manure, which in most cases is released into the environment (Looft et al., 2012; Johnson et al., 2016). Additionally, antibiotic administration patterns and quantities used in food animal production vary considerably from country to country, region to region, and farm to farm, resulting in substantial differences in the rate of resistance recorded in many studies (Van Boeckel et al., 2015). Studies conducted within South Africa and other countries have reported varying levels of $E$. coli resistance to the antibiotics included in the current study.

Overall, the E. coli isolates examined in this study expressed the highest percentage of resistance to tetracycline $(78.1 \%)$, followed by chloramphenicol (63.5\%), ampicillin (58.3\%), and trimethoprim-sulfamethoxazole (39.6\%), correlating with the frequent use of doxycycline and trimethoprim-sulphadiazine in poultry farms in KwaZulu-Natal Province, South Africa. Furthermore, two surveys carried out in South Africa on antimicrobial use in food animals showed that the highly consumed antibiotics in food animal production in South Africa include the macrolides, tetracyclines, sulphonamides, and the penicillins (Henton et al., 2011; Eagar et al., 2012). Therefore, the increased detection of $E$. coli resistant to these four antibiotics (tetracycline, ampicillin, chloramphenicol, and trimethoprim-sulfamethoxazole) in the soil after the litter amendment suggests emergence on the farm followed by transmission of antibiotic-resistant E. coli and/or ARGs from the chicken litter to the soil.

The high prevalence of chloramphenicol resistance was not expected. This antibiotic is not permitted for use in food-animal production in South Africa (Eagar et al., 2012), neither is it among the antibiotics used on the poultry farms in KwaZulu-Natal (personal communication). Therefore, the high chloramphenicol resistance in the absence of chloramphenicol selection pressure may be due to co-selection and/or cotransmission of chloramphenicol resistance due to genetic linkage to genes conferring resistance to antibiotics that are commonly used in poultry farms. For example, the coselection of chloramphenicol resistance with resistance to sulfamethoxazole, tetracycline, and kanamycin due to frequent use of sulphonamides, aminoglycosides, and tetracyclines in food animals has been reported in the United States (Bischoff et al.,
2005). The study demonstrated the conjugative transfer of the chloramphenicol resistance gene $\mathrm{CmlA}$ with both sulphonamide (sul) and aminoglycoside (aadA) resistance genes on class 1 integrons from swine-borne $E$. coli donors to the recipient E. coli strains (Bischoff et al., 2005). Since aminoglycosides are not used in food-animal production in South Africa, the common use of sulphonamides may be responsible for the spread of chloramphenicol resistance among the isolates.

Although the resistance of $E$. coli to the third-generation cephalosporins (cefotaxime and ceftriaxone) was relatively low compared to tetracycline, chloramphenicol, ampicillin, and trimethoprim-sulfamethoxazole, the high frequency observed in chicken litter isolates needs urgent monitoring as cephalosporins are important front-line antibiotics widely used to treat infections caused by Gram-negative bacteria in humans. Thus, to curb the spread of AMR in food animal production and the environment, there is a need to implement policies that will ensure strict and proper use of available antibiotics.

In this study, the chicken litter application significantly increased the detection of antibiotic-resistant E. coli in the soil. This could be ascribed to the combined proliferation of indigenous soil E. coli and exogenous manure-borne ones, both of which were enhanced by the added nutrients from the chicken litter. These findings are consistent with previous studies that have indicated that land application of animal manure can result in the introduction of new ARB and ARGs of animal manure origin to the soil or increase the quantity of already existing soil ARB and ARGs (Sengeløv et al., 2003a; UdikovicKolic et al., 2014). Udikovic-Kolic et al. (2014), in a field experiment conducted in the United States, showed that cow manure amendment increased $\beta$-lactam-resistant bacteria in the manured soil. The increase was attributed to the enrichment of the ARB initially present in the soil. Another field experiment conducted on four farms in Denmark indicated that the temporary increase in tetracycline-resistant Gram-negative bacteria in the soil after the spread of pig manure slurry was due to resistant intestinal bacteria of manure origin (Sengeløv et al., 2003a).

E. coli isolates were only detectable until 42 days following manure application. This short-term detection suggests that E. coli is only suitable as a good indicator of recent or shortterm AMR pollution in agricultural soil environments. Although E. coli was not found in the soil after 42 days following manure amendments, it is not certain if its resistance genes were still present in the litter-amended soil. Thus, studies to determine if $E$. coli-associated resistance genes would survive long in the environment should be conducted, as these could be transferred horizontally to closely related bacteria (Poole et al., 2017).

\section{Multidrug Resistance and Multiple Antibiotic Resistance (MAR) Index of the E. coli Isolates}

In this study, $54.2 \%$ of the $E$. coli isolates were MDR, with the highest rate $(61.5 \%)$ in the litter-amended soil. The highest number and most diverse resistance patterns in soil were recorded on the day of 
litter application (day 0), suggesting a major influx of MDR E. coli from the litter into the soil environment. Furthermore, similar resistance patterns in the litter-amended soil and the chicken litter indicates possible transmission and mobility of ARGs between the litter-borne $E$. coli and the E. coli present in soil throughout sample collection. Therefore, the presence of MDR E. coli up to 77 days in the stored chicken litter heap on the sugarcane field is of great concern, as it can be a source of continuous MDR E. coli contamination to the soil environment, plants, the drainage channel on the field and surrounding water bodies through run-off.

The MAR indexing method is a simple and cost-effective indicator of ABR trends (Osundiya et al., 2013; Sandhu et al., 2016). This study showed that $60 \%, 22 \%$, and $10 \%$ of the isolates from the chicken litter, litter-amended soil, and soil before litter amendment had a MARI $>0.2$, indicating that they originated from environments of high antibiotic exposure (Krumperman, 1983). The average MAR index of 0.25 observed in the chicken litter isolates in this study further attests to the high usage of antibiotics in the poultry farm where the chicken litter was obtained. Furthermore, the relatively high percentage $(51.4 \%)$ of isolates with MAR index $>0.2$ in the litter-amended soil compared to the soil before the litter amendment $(2.7 \%)$ shows that the application of chicken litter resulted in soil contamination with $E$. coli from sources with high use of antibiotics. The MAR indices intimate that the litter-amended soil and the chicken litter should be considered significant reservoirs of MDR E. coli and chicken litter should undergo pre-treatment (e.g., composting) before it is used as fertiliser.

\section{CONCLUSION}

The present study show that chicken litter is a major reservoir of antibiotic-resistant $E$. coli that can be transferred to soil. The increase in the number of antibiotic-resistant $E$. coli following litter application suggests a significant influx of resistant $E$. coli from the chicken litter to litter-amended soil. The higher number of isolates with MAR index $>0.2$ in the litter-amended soil compared to the soil samples collected before the litter amendment indicates soil contamination with $E$. coli from sources with high use of antibiotics such as the chicken litter. Finally, relying on E. coli alone to predict the effect of chicken litter application on AMR in the environment would only provide short-term evidence; other persistent organisms like enterococci should be included in monitoring schemes to understand the long-term effects. The presence of MDR E. coli with resistance to antibiotics of clinical importance in agricultural environment constitutes a serious danger to public health including the local communities, consumers of farm produces and occupationally exposed individuals. Thus, to reduce the prevalence and dissemination of ARB in agricultural environment, biosecurity measures that will ensure prudent use of antibiotics in food animal production and pre-treatment of animal manure (composting or anaerobic digestion) which reduces AMR in manure should be put in place in South Africa. Further studies on other sources of pollutants contributing to the load of clinically relevant antibiotics and ARB in agricultural environment are highly needed.

\section{ETHICS STATEMENT}

Ethical approval was obtained from the Animal Research Ethics Committee (reference AREC 073/016PD) and the Biomedical Research Ethics Committee (reference BCA444/ 16) of the University of KwaZulu-Natal (UKZN). The study is registered with the South African National Department of Agriculture, Forestry, and Fisheries [reference 12/11/1/ 5 (879)].

\section{AUTHOR CONTRIBUTIONS}

DF, AA, and SE: co-conceptualized the study. DF: undertook sample collection, performed the laboratory experiments and wrote the manuscript. DF, AA, and DA: analysed the data. AA and SE: supervised the project. SE: facilitated ethical approval and vetted the data analysis. All authors undertook a critical revision of the manuscripts.

\section{FUNDING}

This research was funded by the WHO Advisory Group on Integrated Surveillance of Antimicrobial Resistance (AGISAR) Research Project: "Triangulation of Antibiotic Resistance from Humans, the Food Chain and Associated Environments-A One Health Project" (Reference ID: 204517), South African Research Chair Initiative of the Department of Science and Technology and National Research Foundation of South Africa (Grant No. 98342), the South African Medical Research Council (SAMRC) and United Kingdom Medical Research Council, the SAMRC under a Self-Initiated Research Grant and the College of Health Sciences, University of Kwa-Zulu Natal, South Africa. Any opinions, findings, and conclusions, or recommendations expressed in this material are those of the author(s) and do not necessarily reflect the views of the organisations or agencies that provided support for the project. The funders had no role in the study design nor the decision to submit the work for publication.

\section{ACKNOWLEDGMENTS}

The authors would like to thank research assistants Phoebe Eberechi and Zama Kubone for their technical assistance.

\section{SUPPLEMENTARY MATERIAL}

The Supplementary Material for this article can be found online at: https://www.frontiersin.org/articles/10.3389/fenvs.2021.751732/ full\#supplementary-material 


\section{REFERENCES}

Aarestrup, F. M., Wegener, H. C., and Collignon, P. (2008). Resistance in Bacteria of the Food Chain: Epidemiology and Control Strategies. Expert Rev. Antiinfective Ther. 6, 733-750. doi:10.1586/14787210.6.5.733

Abdalla, S. E., Abia, A. L. K., Amoako, D. G., Perrett, K., Bester, L. A., and Essack, S. Y. (2021). From farm-to-fork: E. coli from an Intensive Pig Production System in South Africa Shows High Resistance to Critically Important Antibiotics for Human and Animal Use. Antibiotics 10, 178. doi:10.3390/antibiotics10020178

Abia, A. L. K., Ubomba-Jaswa, E., du Preez, M., and Momba, M. N. B. (2015b). Riverbed Sediments in the Apies River, South Africa: Recommending the Use of Both Clostridium perfringens and Escherichia coli as Indicators of Faecal Pollution. J. Soils Sediments 15, 2412-2424. doi:10.1007/s11368-015-1209-0

Abia, A. L. K., Ubomba-Jaswa, E., and Momba, M. N. B. (2015a). Impact of Seasonal Variation on Escherichia coli Concentrations in the Riverbed Sediments in the Apies River, South Africa. Sci. Total Environ. 537, 462-469. doi:10.1016/j.scitotenv.2015.07.132

Atidégla, S. C., Huat, J., Agbossou, E. K., Saint-Macary, H., and Glèlè Kakai, R. (2016). Vegetable Contamination by the Fecal Bacteria of Poultry Manure: Case Study of Gardening Sites in Southern Benin. Int. J. Food Sci. 2016, 1-8. doi:10.1155/2016/4767453

Bale, M. J., Bennett, P. M., Beringer, J. E., and Hinton, M. (1993). The Survival of Bacteria Exposed to Desiccation on Surfaces Associated with Farm Buildings. J. Appl. Bacteriol. 75 (6), 519-528. doi:10.1111/j.1365-2672.1993.tb01589.x

Berry, E. D., and Miller, D. N. (2005). Cattle Feedlot Soil Moisture and Manure Content: II. Impact on Escherichia coli O157. J. Environ. Qual. 34, 656-663. doi:10.2134/jeq2005.0656

Binh, C. T. T., Heuer, H., Kaupenjohann, M., and Smalla, K. (2008). Piggery Manure Used for Soil Fertilization Is a Reservoir for Transferable Antibiotic Resistance Plasmids. FEMS Microbiol. Ecol. 66, 25-37. doi:10.1111/j.15746941.2008.00526.x

Bischoff, K. M., White, D. G., Hume, M. E., Poole, T. L., and Nisbet, D. J. (2005). The Chloramphenicol Resistance genecmlAis Disseminated on Transferable Plasmids that Confer Multiple-Drug Resistance in swineEscherichia Coli. FEMS Microbiol. Lett. 243, 285-291. doi:10.1016/j.femsle.2004.12.017

Bolton, D. J., Monaghan, A., Byrne, B., Fanning, S., Sweeney, T., and McDowell, D. A. (2011). Incidence and Survival of Non-o157 Verocytotoxigenic Escherichia coli in Soil. J. Appl. Microbiol. 111, 484-490. doi:10.1111/j.13652672.2011.05057.x

Brye, K., Slaton, N., Norman, R., and Savin, M. (2004). Short-term Effects of Poultry Litter Form and Rate on Soil Bulk Density and Water Content. Commun. Soil Sci. Plant Anal. 35, 2311-2325. doi:10.1081/CSS-200030655

Byappanahalli, M. N., Nevers, M. B., Korajkic, A., Staley, Z. R., and Harwood, V. J. (2012). Enterococci in the Environment. Microbiol. Mol. Biol. Rev. 76 (4), 685-706. doi:10.1128/MMBR.00023-12

Çekiç, S. K., De, J., Jubair, M., and Schneider, K. R. (2017). Persistence of Indigenous Escherichia coli in Raw Bovine Manure-Amended Soil. J. Food Prot. 80, 1562-1573. doi:10.4315/0362-028X.JFP-17-033

Chen, Q., An, X., Li, H., Su, J., Ma, Y., and Zhu, Y.-G. (2016b). Long-term Field Application of Sewage Sludge Increases the Abundance of Antibiotic Resistance Genes in Soil. Environ. Int. 92-93, 1-10. doi:10.1016/j.envint.2016.03.026

CLSI (2020). "Performance Standards for Antimicrobial Susceptibility Testing," in Approved Standard M100. 27th ed. (Wayne, PA, USA: Clinical and Laboratory Standards Institute).

Dashti, A. A., Jadaon, M. M., Abdulsamad, A. M., and Dashti, H. M. (2009). Heat Treatment of Bacteria: a Simple Method of DNA Extraction for Molecular Techniques. Kuwait Med. J. 41, 117-122.

Eagar, H., Swan, G., and van Vuuren, M. (2012). A Survey of Antimicrobial Usage in Animals in South Africa with Specific Reference to Food Animals. J. S. Afr. Vet. Assoc. 83 (1), 1-8. doi:10.4102/jsava.v83i1.16

Fatoba, D. O., Abia, A. L. K., Amoako, D. G., Essack, S. Y., and Essack, S. Y. (2021). Rethinking Manure Application: Increase in Multidrug-Resistant Enterococcus Spp. In Agricultural Soil Following Chicken Litter Application. Microorganisms 9 (5), 885. doi:10.3390/microorganisms 9050885

Gao, L., Hu, J., Zhang, X., Wei, L., Li, S., Miao, Z., et al. (2015). Application of Swine Manure on Agricultural fields Contributes to Extended-Spectrum $\beta$-lactamase- producing Escherichia coli Spread in Tai'an, China. Front. Microbiol. 6, 313. doi:10.3389/fmicb.2015.00313

Henton, M. M., Eagar, H. A., Swan, G. E., and Van Vuuren, M. (2011). Part VI. Antibiotic Management and Resistance in Livestock Production. S Afr. Med. J. 101 (8), 583-586.

Heuer, H., Schmitt, H., and Smalla, K. (2011). Antibiotic Resistance Gene Spread Due to Manure Application on Agricultural fields. Curr. Opin. Microbiol. 14, 236-243. doi:10.1016/j.mib.2011.04.009

Heuer, H., and Smalla, K. (2007). Manure and Sulfadiazine Synergistically Increased Bacterial Antibiotic Resistance in Soil over at Least Two Months. Environ. Microbiol. 9 (3), 657-666. doi:10.1111/j.1462-2920.2006.01185.x

Islam, M., Doyle, M. P., Phatak, S. C., Millner, P., and Jiang, X. (2004). Persistence of Enterohemorrhagic Escherichia coli O157:H7 in Soil and on Leaf Lettuce and Parsley Grown in fields Treated with Contaminated Manure Composts or Irrigation Water. J. Food Prot. 67, 1365-1370. doi:10.4315/0362-028x-67.7.1365

Jechalke, S., Kopmann, C., Rosendahl, I., Groeneweg, J., Weichelt, V., Krögerrecklenfort, E., et al. (2013). Increased Abundance and Transferability of Resistance Genes after Field Application of Manure from SulfadiazineTreated Pigs. Appl. Environ. Microbiol. 79, 1704-1711. doi:10.1128/ AEM.03172-12

Jensen, A. N., Storm, C., Forslund, A., Baggesen, D. L., and Dalsgaard, A. (2013). Escherichia coli Contamination of Lettuce Grown in Soils Amended with Animal Slurry. J. Food Prot. 76, 1137-1144. doi:10.4315/0362-028X.JFP-13-011

Johnson, T. A., Stedtfeld, R. D., Wang, Q., Cole, J. R., Hashsham, S. A., Looft, T., et al. (2016). Clusters of Antibiotic Resistance Genes Enriched Together Stay Together in Swine Agriculture. MBio 7, e02214-15. doi:10.1128/mBio.02214-15

Krumperman, P. H. (1983). Multiple Antibiotic Resistance Indexing of Escherichia coli to Identify High-Risk Sources of Fecal Contamination of Foods. Appl. Environ. Microbiol. 46, 165-170. doi:10.1128/aem.46.1.165-170.1983

Kyakuwaire, M., Olupot, G., Amoding, A., Nkedi-Kizza, P., and Basamba, T. A. (2019). How Safe Is Chicken Litter for Land Application as an Organic Fertilizer? A Review. Ijerph 16 (19), 3521. doi:10.3390/ijerph16193521

Laxminarayan, R., Duse, A., Wattal, C., Zaidi, A. K. M., Wertheim, H. F. L., Sumpradit, N., et al. (2013). Antibiotic Resistance-The Need for Global Solutions. Lancet Infect. Dis. 13, 1057-1098. doi:10.1016/S1473-3099(13) 70318-9

Looft, T., Johnson, T. A., Allen, H. K., Bayles, D. O., Alt, D. P., Stedtfeld, R. D., et al. (2012). In-feed Antibiotic Effects on the Swine Intestinal Microbiome. Proc. Natl. Acad. Sci. 109, 1691-1696. doi:10.1073/pnas.1120238109

López-Saucedo, C., Cerna, J. F., Villegas-Sepulveda, N., Thompson, R., Velazquez, F. R., Torres, J., et al. (2003). Single Multiplex Polymerase Chain Reaction to Detect Diverse Loci Associated with DiarrheagenicEscherichia Coli. Emerg. Infect. Dis. 9, 127-131. doi:10.3201/eid0901.010507

Marti, R., Scott, A., Tien, Y.-C., Murray, R., Sabourin, L., Zhang, Y., et al. (2013). Impact of Manure Fertilization on the Abundance of Antibiotic-Resistant Bacteria and Frequency of Detection of Antibiotic Resistance Genes in Soil and on Vegetables at Harvest. Appl. Environ. Microbiol. 79, 5701-5709. doi:10.1128/AEM.01682-13

Marti, R., Tien, Y.-C., Murray, R., Scott, A., Sabourin, L., and Topp, E. (2014). Safely Coupling Livestock and Crop Production Systems: How Rapidly Do Antibiotic Resistance Genes Dissipate in Soil Following a Commercial Application of Swine or Dairy Manure? Appl. Environ. Microbiol. 80, 3258-3265. doi:10.1128/aem.00231-14

Mbelle, N. M., Feldman, C., Osei Sekyere, J., Maningi, N. E., Modipane, L., and Essack, S. Y. (2019). The Resistome, Mobilome, Virulome and Phylogenomics of Multidrug-Resistant Escherichia coli Clinical Isolates from Pretoria, South Africa. Sci. Rep. 9 (1), 1-16. doi:10.1038/s41598-019-52859-2

McIver, K. S., Amoako, D. G., Abia, A. L. K., Bester, L. A., Chenia, H. Y., and Essack, S. Y. (2020). Molecular Epidemiology of Antibiotic-Resistant Escherichia coli from Farm-To-fork in Intensive Poultry Production in KwaZulu-Natal, South Africa. Antibiotics 9, 850. doi:10.3390/ antibiotics9120850

Merchant, L. E., Rempel, H., Forge, T., Kannangara, T., Bittman, S., Delaquis, P., et al. (2012). Characterization of Antibiotic-Resistant and Potentially Pathogenic Escherichia coli from Soil Fertilized with Litter of Broiler Chickens Fed Antimicrobial-Supplemented Diets. Can. J. Microbiol. 58 (9), 1084-1098. doi:10.1139/w2012-082 
Muurinen, J., Stedtfeld, R., Karkman, A., Pärnänen, K., Tiedje, J., and Virta, M. (2017). Influence of Manure Application on the Environmental Resistome under Finnish Agricultural Practice with Restricted Antibiotic Use. Environ. Sci. Technol. 51 (11), 5989-5999. doi:10.1021/acs.est.7b00551

Osundiya, O. O., Oladele, R. O., and Oduyebo, O. O. (2013). Multiple Antibiotic Resistance (MAR) Indices of Pseudomonas and Klebsiella Species Isolates in Lagos University Teaching Hospital. Afr. J. Clin. Exp. Microbiol. 14, 164-168. doi:10.4314/ajcem.v14i3.8

Poole, T. L., Callaway, T. R., Norman, K. N., Scott, H. M., Loneragan, G. H., Ison, S. A., et al. (2017). Transferability of Antimicrobial Resistance from MultidrugResistant Escherichia coli Isolated from Cattle in the USA to E. coli and Salmonella Newport Recipients. J. Glob. Antimicrob. Resist. 11, 123-132. doi:10.1016/j.jgar.2017.08.001

Robins-Browne, R. M. (2005). The Relentless Evolution of Pathogenic Escherichia coli. Clin. Infect. Dis. 41, 793-794. doi:10.1086/432725

Sandhu, R., Dahiya, S., and Sayal, P. (2016). Evaluation of Multiple Antibiotic Resistance (MAR) index and Doxycycline Susceptibility of Acinetobacter Species Among Inpatients. Ind. Jour. Microb. Res. 3, 299-304. doi:10.5958/ 2394-5478.2016.00064.9

Sengeløv, G., Agersø, Y., Halling-Sørensen, B., Baloda, S. B., Andersen, J. S., and Jensen, L. B. (2003a). Bacterial Antibiotic Resistance Levels in Danish farmland as a Result of Treatment with Pig Manure Slurry. Environ. Int. 28, 587-595. doi:10.1016/s0160-4120(02)00084-3

Sengeløv, G., Halling-Sørensen, B., and Aarestrup, F. M. (2003b). Susceptibility of Escherichia coli and Enterococcus Faecium Isolated from Pigs and Broiler Chickens to Tetracycline Degradation Products and Distribution of Tetracycline Resistance Determinants in E. coli from Food Animals. Vet. Microbiol. 95, 91-101. doi:10.1016/S0378-1135(03)00123-8

Shonhiwa, A. M., Ntshoe, G., Essel, V., Thomas, J., and McCarthy, K. (2019). A Review of Foodborne Diseases Outbreaks Reported to the Outbreak Response Unit, National institute for Communicable Diseases, South Africa, 2013-2017. Int. J. Infect. Dis. 79, 73-150. doi:10.1016/j.ijid.2018.11.186

Sun, Y., Snow, D., Walia, H., and Li, X. (2021). Transmission Routes of the Microbiome and Resistome from Manure to Soil and Lettuce. Environ. Sci. Technol. 55 (16), 11102-11112. doi:10.1021/acs.est.1c02985

Tyagi, V., and Chopra, A. (2006). Alternative Microbial Indicators of Faecal Pollution: Current Perspective. Iran. J. Environ. Heal. Sci. Eng. 3, 205-216.

Udikovic-Kolic, N., Wichmann, F., Broderick, N. A., and Handelsman, J. (2014). Bloom of Resident Antibiotic-Resistant Bacteria in Soil Following Manure Fertilization. Proc. Natl. Acad. Sci. USA 111, 15202-15207. doi:10.1073/ pnas. 1409836111

Van Boeckel, T. P., Brower, C., Gilbert, M., Grenfell, B. T., Levin, S. A., Robinson, T. P., et al. (2015). Global Trends in Antimicrobial Use in Food Animals. Proc. Natl. Acad. Sci. USA 112, 5649-5654. doi:10.1073/pnas.1503141112
Wellcome Trust (2018). Initiatives for Addressing Antimicrobial Resistance in the Environment: Current Situation and Challenges. Available at: https:// wellcome.ac.uk/sites/default/files/antimicrobial-resistance-environmentreport.pdf.

WHO (2020). Antimicrobial Resistance. Available at: https://www.who.int/ news-room/fact-sheets/detail/antimicrobial-resistance (Accessed on July 13th, 2021).

Williams, A. P., Avery, L. M., Killham, K., and Jones, D. L. (2005). Persistence of Escherichia coli $\mathrm{O} 157$ on Farm Surfaces under Different Environmental Conditions. J. Appl. Microbiol. 98, 1075-1083. doi:10.1111/j.13652672.2004.02530.x

Yang, Y., Li, X., Liu, J., Zhou, Z., Zhang, T., and Wang, X. (2017). Bacterial Diversity as Affected by Application of Manure in Red Soils of Subtropical China. Biol. Fertil. Soils 53, 639-649. doi:10.1007/s00374-017-1209-x

Zhang, Y.-J., Hu, H.-W., Chen, Q.-L., Singh, B. K., Yan, H., Chen, D., et al. (2019). Transfer of Antibiotic Resistance from Manure-Amended Soils to Vegetable Microbiomes. Environ. Int. 130, 104912. doi:10.1016/ j.envint.2019.104912

Zhu, Y.-G., Johnson, T. A., Su, J.-Q., Qiao, M., Guo, G.-X., Stedtfeld, R. D., et al. (2013). Diverse and Abundant Antibiotic Resistance Genes in Chinese Swine Farms. Proc. Natl. Acad. Sci. USA 110 (9), 3435-3440. doi:10.1073/ pnas. 1222743110

Conflict of Interest: SE is the chairperson of Global Respiratory Infection Partnership and a member of the Global Hygiene Council, funded by unrestricted educational grants from Reckitt and Benckiser Ltd., United Kingdom.

The remaining authors declare that the research was conducted in the absence of any commercial or financial relationships that could be construed as a potential conflict of interest.

Publisher's Note: All claims expressed in this article are solely those of the authors and do not necessarily represent those of their affiliated organizations, or those of the publisher, the editors, and the reviewers. Any product that may be evaluated in this article, or claim that may be made by its manufacturer, is not guaranteed or endorsed by the publisher.

Copyright (c) 2022 Fatoba, Amoako, Abia and Essack. This is an open-access article distributed under the terms of the Creative Commons Attribution License (CC BY). The use, distribution or reproduction in other forums is permitted, provided the original author(s) and the copyright owner(s) are credited and that the original publication in this journal is cited, in accordance with accepted academic practice. No use, distribution or reproduction is permitted which does not comply with these terms. 